\title{
Locally Excited State-Charge Transfer State Coupled Dyes as Optically Responsive Neuron Firing Probes
}

\author{
Dumitru Sirbu, ${ }^{[a]}$ John B. Butcher, ${ }^{[b]}$ Paul G. Waddell, ${ }^{[c]}$ Peter Andras, ${ }^{[b]}$ and Andrew C. Benniston ${ }^{[a]}$
}

\begin{abstract}
A selection of NIR-optically responsive neuron probes were produced comprising of a donor julolidyl group connected to a BODIPY core and several different styryl and vinylpyridinyl derived acceptor moieties. The strength of the donor-acceptor interaction was systematically modulated by altering the electron withdrawing nature of the aryl unit. The fluorescence quantum yield was observed to decrease as the electron withdrawing effect of the aryl subunit increased in line with changes of the Hammett coefficients. The effectiveness of these fluorophores as optically responsive dyes for neuronal imaging was assessed by measuring the toxicity and signalto-noise ratio (SNR) of each dye. The mechanism for the optical response is disparate from conventional cyanine-based dyes opening up a new way to produce effective voltage sensitive dyes that respond well into the NIR region.
\end{abstract}

\section{Introduction}

Multifunctional dyes with a push-pull architecture are often associated with various interesting physical properties such as strong charge-transfer (CT) character, ${ }^{[1]}$ large dipole moments in the ground and excited state, ${ }^{[2]}$ non-linear optical (NLO) behaviour, ${ }^{[3]}$ solvatochromism ${ }^{[4]}$ and long-range electron transfer. ${ }^{[5]}$ In this context, boron dipyrromethene (BODIPY) based dyes have proven to be exceptionally beneficial due to their highly adaptable photophysical properties. ${ }^{[6]}$ Bespoke BODIPY molecules exhibiting CT character have been proposed as candidates for various applications such as fluorescence probes (in solution and living tissues) and visible light harvesting. ${ }^{[7]} \mathrm{We}$ have been especially interested in new dyes with CT character for application as optically responsive voltage sensitive dyes (VSDs) for neural imaging. Within the field of VSDs, zwitterionic dyes such as di-4-ANEPPS ${ }^{[8]}$ are most commonly used but are far from

[a] Dr D. Sirbu, Prof A. C. Benniston Molecular Photonics Laboratory

School of Chemistry

Newcastle University, Newcastle upon Tyne, NE1 7RU, UK

E-mail: andrew.benniston@ncl.ac.uk

[b] Dr J. B. Butcher, Prof P. Andras

School of Computing and Mathematics

Keele University

Keele, ST5 8BG, UK

[c] Dr P. G. Waddell

Crystallography Laboratory

School of Chemistry

Newcastle University, Newcastle upon Tyne, NE1 7RU, UK

Supporting information for this article is given via a link at the end of the document perfect. VSDs are an alternative technology within the field of neuronal imaging providing superior time-resolution when compared to $\mathrm{Ca}^{2+}$ responsive dyes, but suffer from an inferior signal-to-noise (SNR) ratio that is roughly 10 times less than that offered by most $\mathrm{Ca}^{2+}$ dyes. The ultimate aim, therefore, is to try and improve the responsivity of VSDs in terms of SNR while maintaining their fast time-resolution and keeping their toxicity low. In the search for new superior VSDs our attention turned to BODIPY derivatives which displayed strong CT character and were emissive from a locally excited state (LES). The premise was that $\mathrm{CT}$ within the molecular framework would respond to strong electric fields and perturb mixing with the LES. The optical response would therefore not follow the conventional Stark Effect approach of most VSDs which rely on direct charge transfer emission that is often weak. Our first rudimentary model dyad system, based on a julolidyl donor linked to an unsubstituted $\mathrm{BF}_{2^{-}}$ dipyrromethene subunit, showed exceptionally strong CT character. ${ }^{[7 \mathrm{e}]}$ The charge density distribution within the dyad was evident by a solvent effect, and ${ }^{13} \mathrm{C}$ NMR chemical shifts could be fitted adequately to a polarity model. ${ }^{[7 \mathrm{~d}]}$ Although the electrical firing of neurons in crab ganglions could be monitored by a fluorescence intensity modulation, the changes were still rather modest. In an attempt to enhance this effect we present a series of new BODIPY dyes incorporating the julolidyl donor unit that gives rise to a very pronounced charge-transfer absorption in the red region. The introduction of the styryl unit strongly affects the $\mathrm{S}_{0} \rightarrow \mathrm{S}_{1}$ electronic transition so that $\mathrm{HOMO}$ and $\mathrm{HOMO}-1$ are very close in energy, as revealed by electronic absorption spectroscopy and DFT molecular modelling calculations. The introduction of electron withdrawing groups allowed for fine-tuning of the molecule's photophysical properties that results in significant SNR enhancement as compared to the first generation of BODIPY based VSDs. The best dye, JULBD6, is on par with the benchmark cyanine-based di-4-ANEPPS VSD but is responsive into the NIR.
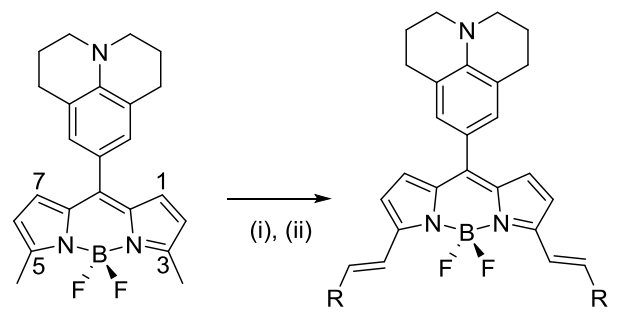

JULBD1, $\mathrm{R}=\mathrm{Ph}$ JULBD2, $\mathrm{R}=p-\mathrm{PhCO}_{2} \mathrm{H}$ JULBD3, $\mathrm{R}=p-\mathrm{PhCN}$ JULBD4, $\mathrm{R}=p-\mathrm{PhNO}_{2}$ JULBD5, $\mathrm{R}=p-\mathrm{Py}$ JULBD6, R = N-Me $p-\mathrm{Py}$

Scheme 1. Reagents and Conditions: (i) $\mathrm{CH}_{3} \mathrm{CN}$, molecular sieves, piperidine, acetic acid, yields: JULBD1 70\%, JULBD2 44\%, JULBD3 13\%, JULBD4 10\%, JULBD5 $49 \%$; (ii) $\mathrm{CH}_{3} \mathrm{CN}$, Mel, yield JULBD6 75\%. Note: selected numbering of the dipyrromethene unit is also shown. 


\section{Results and Discussion}

\section{Synthesis}

The design of the new dyes is based on $\pi$-extension of the 3,5 positions of the BODIPY subunit which is well documented in the literature. ${ }^{[9]}$ Compounds JULBD1-5 were synthesised by a modified literature procedure, ${ }^{[10]}$ which employed an acid/base catalysed condensation of an aldehyde with the dimethyl-BODIPY 1. Reactions were easily monitored due to the colour change from purple to deep blue as the starting material was consumed. While the usual purification procedure for a product from a BODIPY condensation reaction involves extensive column chromatography to separate the mono-functionalised product, it should be noted that compounds JULBD1 and JULBD2 were obtained using chromatography-free purification procedures in relatively high yields. The other three compounds JULBD3-5 did require careful silica gel column chromatography and this is one reason for their low yields. JULBD6 was obtained in a good yield by methylation of JULBD5 with Mel in $\mathrm{CH}_{3} \mathrm{CN}$.

All compounds were characterized by high-field NMR spectroscopy including ${ }^{1} \mathrm{H},{ }^{13} \mathrm{C},{ }^{11} \mathrm{~B}$ and ${ }^{19} \mathrm{~F}$ nuclei (see Supporting Information). The unequivocal identification of two doublets with high $\mathrm{J}$ coupling constants $(16.2-16.4 \mathrm{~Hz})$ for JULBD1 and JULBD3-6 are consistent with all-trans double bonds from the condensation reaction. An exception is the carboxylic acid substituted derivative JULBD2 which displayed a broad singlet at $7.69 \mathrm{ppm}$, which would suggest that there is accidental equivalence of the proton signals. The triplet $(J=31-33 \mathrm{~Hz})$ in ${ }^{11} \mathrm{~B}$ NMR spectra and the quartet in the ${ }^{19} \mathrm{~F}$ NMR spectra $(J=31$ - $33 \mathrm{~Hz}$ ) are typical for $\mathrm{BF}_{2}$ complexes, and together with mass spectrometry results (see Supporting Information) corroborated the proposed structures. The additional doublet at $-70.1 \mathrm{ppm}(\mathrm{J}=$ $711 \mathrm{~Hz}$ ), found in the ${ }^{19} \mathrm{~F}$ NMR spectrum of JULBD6 is consistent with the $\mathrm{PF}_{6}-$ anions. The positive ion mass spectra of JULBD1, JULBD3 and JULBD4 consisted of a mixture of $[\mathrm{M}]^{+}$and $[\mathrm{M}+\mathrm{H}]^{+}$ molecular ion patterns, while the compound JULBD5 showed only the $[\mathrm{M}+\mathrm{H}]^{+}$ion. The negative ion mass spectrum of JULBD2 showed the $[\mathrm{M}-\mathrm{H}]^{-}$ion typical for a carboxylic derivative. The [M$\mathrm{F}]^{+},[2 \mathrm{M}+\mathrm{H}]^{+}$ions in the positive mode and $[\mathrm{M}-2 \mathrm{H}]^{2-},[\mathrm{M}-2 \mathrm{H}+\mathrm{Na}]^{-}$ ions in the negative mode MS were also identified. The positive ion mass spectrum of JULBD6 consisted of the $\left[\mathrm{M}-\mathrm{PF}_{6}\right]^{+}$and $[\mathrm{M}$ $\left.2 \mathrm{PF}_{6}\right]^{2+}$ cations.

\section{$X$-ray Crystallography}

As further characterization of the compounds, crystals suitable for analysis by single-crystal $X$-ray diffraction could be grown for two of the derivatives. The structures of JULBD3 and JULBD4 unequivocally confirm their identity. Both compounds crystallise in the centrosymmetric, triclinic space group $\mathrm{P}-1$ as solvates with $\mathrm{CH}_{2} \mathrm{Cl}_{2}$ and $\mathrm{CHCl}_{3}$ in the case of JULBD3 and JULBD4, respectively. The solvent molecules in both structures have been modelled as disordered over multiple sites. The molecular structure of JULBD3 is illustrated in Figure 1, and selected bond lengths and angles are shown in Table 1. The two trans $C=C$ bonds are confirmed by the X-ray analysis and, as observed in previous structures, the julolidyl subunit is twisted with respect to the dipyrromethene core (torsion angle C10-C8-C29-C30 = $\left.43.7(2)^{\circ}\right)$. It is noted that the two propyl moieties of the julolidyl group are in an anti-arrangement (Figure 1B) and form a chairlike conformation. The front view (Figure 1C) clearly shows that the two cyano-styryl subunits are slightly out-of-plane with respect to the BODIPY core; angles between planes created using the BODIPY subunit and each aryl ring are ca. $6.3^{\circ}$ and $21.7^{\circ}$. Evidently the bend is more pronounced on the right-hand side of the diagram. The crystal packing diagram (see Supporting Information) reveals that the molecular units pack in a head-to-tail arrangement along the b-axis; the N5-F2 separation distance between adjacent groups is $4.149(2) \AA$. When viewed along the a-axis, a similar head-to-tail arrangement is also observed in the $\mathrm{CH}_{2} \mathrm{Cl}_{2}$ molecules located between the planes.
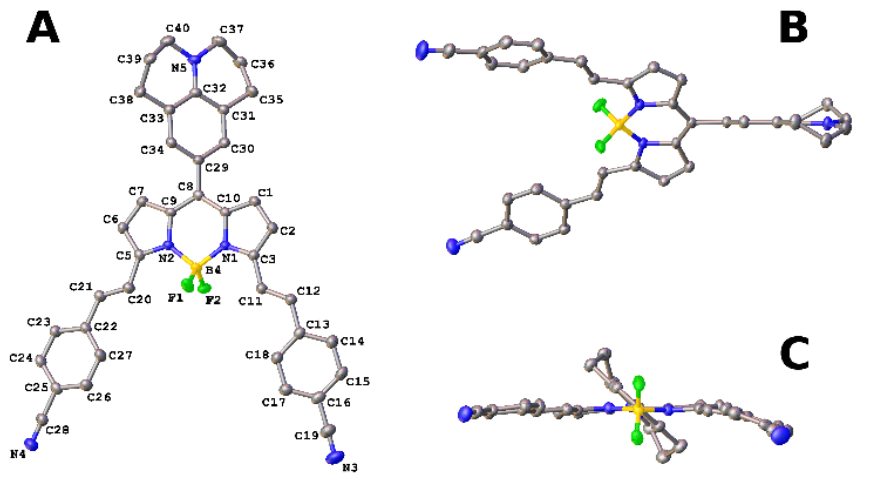

Figure 1. X-ray crystal structure of JULBD3 (A), an orientation highlighting the conformation of the julolidyl moiety (B) and another illustrating the twisting of the julolidyl and out-of-plane nature of the alkenyl-aryl groups (C). All displacement ellipsoids are drawn at the $50 \%$ probability level. Hydrogen atoms and the $\mathrm{CH}_{2} \mathrm{Cl}_{2}$ solvent molecules are omitted for clarity.

Table 1. Selected bond lengths and angles for JULBD3.

\begin{tabular}{|c|c|c|c|}
\hline Atoms & $\begin{array}{l}\text { Bond } \\
\text { Length/ } \AA\end{array}$ & Atoms & $\begin{array}{l}\text { Bond } \\
\text { Angle/ }{ }^{\circ}\end{array}$ \\
\hline B-F & $\begin{array}{l}1.390(2) \\
1.395(2) \\
1.340^{[a]}\end{array}$ & F1-B4-F2 & $\begin{array}{l}108.79(14) \\
109.40^{\text {[a] }}\end{array}$ \\
\hline N-B & $\begin{array}{l}1.547(2), \\
1.543(2) \\
1.554^{\text {[a] }}\end{array}$ & N2-B4-N1 & $\begin{array}{l}106.82(13) \\
106.86^{\text {[a] }}\end{array}$ \\
\hline $\mathrm{C}=\mathrm{C}_{\text {trans }}$ & $\begin{array}{l}1.340(3), \\
1.338(3) \\
1.350^{\text {[a] }}\end{array}$ & N4-C28-C25 & $\begin{array}{l}177.6(2) \\
179.9^{\text {[a] }}\end{array}$ \\
\hline $\mathrm{C} \equiv \mathrm{N}$ & $\begin{array}{l}1.143(3), \\
1.147(2) \\
1.157^{\text {[a] }}\end{array}$ & N3-C19-C16 & $\begin{array}{l}178.5(2) \\
179.9^{[\mathrm{a}]}\end{array}$ \\
\hline N5-C32 & $\begin{array}{l}1.372(2) \\
1.373^{\text {[a] }} \\
\end{array}$ & C10-C8-C29-C30 & $\begin{array}{l}43.7(2) \\
49.1^{[a]}\end{array}$ \\
\hline
\end{tabular}

[a] Values calculated using DFT (B3PW91) and the 6-311+G(d, p) basis set in the gas phase. 
The molecular structure for JULBD4 is illustrated in Supporting Information along with selected bond lengths and angles. A noteworthy point is the location of the $\mathrm{CHCl}_{3}$ molecule, which sits in a cleft between the two nitro-styryl arms. The julolidyl subunit is again found to be twisted with respect to the dipyrromethene core though slightly greater than seen in JULBD3.
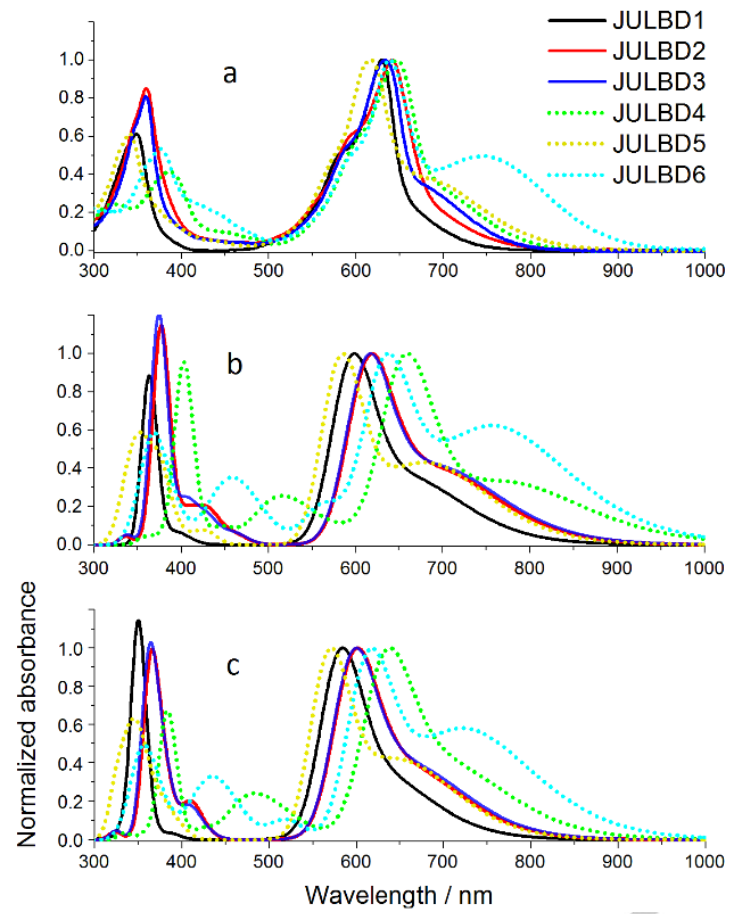

Figure 2. UV-Vis-NIR absorption spectra for compounds JULBD1-6 in DMSO: experimental values (a) and DFT calculated using IEF-PCM solvent model at B3PW91/6-311+G(d,p) (b) and mPW1PW91/6-311+G(d,p) (c) theoretical levels.
Table 2. Room temperature UV-Vis-NIR absorption and emission parameters for JULB1-6 in dimethylsulfoxide (DMSO).

\begin{tabular}{|c|c|c|c|c|c|}
\hline Compound & $\begin{array}{l}\lambda_{\mathrm{ABS}} \\
/ \mathrm{nm}\end{array}$ & $\begin{array}{l}\lambda_{\mathrm{ABS}^{[\mathrm{a}]}} \\
/ \mathrm{nm}\end{array}$ & $\begin{array}{l}\lambda_{\mathrm{EM}} \\
/ \mathrm{nm}\end{array}$ & $\begin{array}{l}\text { Stokes } \\
\text { Shift / } \\
\mathrm{cm}^{-1}\end{array}$ & $\begin{array}{l}\phi F L U^{[b]} \\
/ \%\end{array}$ \\
\hline JULBD1 & $\begin{array}{l}349,580^{\text {sh }}, \\
630,690^{\text {sh }}\end{array}$ & $\begin{array}{l}572,594, \\
614,{ }^{[c]} \\
628\end{array}$ & $\begin{array}{l}653 \\
710^{\text {sh }}\end{array}$ & $\begin{array}{l}559 \\
610^{[d]}\end{array}$ & $21 \pm 0.1$ \\
\hline JULBD2 & $\begin{array}{l}362,590^{\text {sh }}, \\
641\end{array}$ & $\begin{array}{l}556,596, \\
632,{ }^{[c]} \\
641\end{array}$ & $\begin{array}{l}658 \\
721\end{array}$ & $\begin{array}{l}403, \\
403^{[d]}\end{array}$ & $6 \pm 0.1$ \\
\hline JULBD3 & $\begin{array}{l}345^{\text {sh }}, 359 \\
590^{\text {sh }}, 634, \\
710^{\text {sh }}\end{array}$ & $\begin{array}{l}572,596, \\
633,642^{[\mathrm{c}]}\end{array}$ & $\begin{array}{l}660 \\
729\end{array}$ & $\begin{array}{l}621 \\
646^{[d]}\end{array}$ & $3 \pm 0.1$ \\
\hline JULBD4 & $\begin{array}{l}324,386^{\text {br }} \\
450^{\text {sh }}, 600^{\text {sh }} \\
647,730^{\text {sh }}\end{array}$ & $\begin{array}{l}567,603, \\
646, \\
661^{\text {[c] }}\end{array}$ & $\begin{array}{l}683 \\
755^{\text {sh }}\end{array}$ & $\begin{array}{l}815 \\
839^{[d]}\end{array}$ & $1.3 \pm 0.2$ \\
\hline JULBD5 & $\begin{array}{l}260, \quad 570^{\text {sh }} \\
616,690^{\text {sh }}\end{array}$ & $\begin{array}{l}552,578, \\
616, \\
661^{[\mathrm{c}]}\end{array}$ & $\begin{array}{l}653 \\
696^{\text {sh }} \\
732^{\text {sh }}\end{array}$ & $\begin{array}{l}919 \\
919^{[d]}\end{array}$ & $1.0 \pm 0.2$ \\
\hline JULBD6 & $\begin{array}{l}277, \quad 376, \\
433^{\text {sh }}, 590^{\text {sh }}, \\
639,745^{\text {sh }}\end{array}$ & $\begin{array}{l}541,590, \\
639, \\
741^{[c]}\end{array}$ & $\begin{array}{l}684 \\
760^{\text {sh }}\end{array}$ & $\begin{array}{l}1030 \\
1030^{[d]}\end{array}$ & $0.4 \pm 0.2$ \\
\hline
\end{tabular}

[a] Data obtained by deconvolution of the absorption spectra. [b] Quantum yields calculated relative to $\mathrm{H}_{2}$ TPP in ethanol under $\mathrm{N}_{2}\left(\Phi_{\mathrm{FLU}}=11 \%\right)$. [c] The CT absorption band. [d] The Stokes Shift calculated versus the deconvoluted BODIPY absorption band. sh = shoulder, $\mathrm{br}=$ broad.

\section{Absorption and Fluorescence Spectroscopies}

Room temperature electronic absorption spectra for JULBD16 in DMSO are shown in Figure 2 with relevant parameters presented in Table 2. The spectrum for JULBD1 shows strongly red-shifted BODIPY patterns and comprises a band on the edge of the near-UV region at $\lambda_{\max }=349 \mathrm{~nm}$, and a strong band in the red region at $\lambda_{\max }=630 \mathrm{~nm}$ with a vibrational shoulder on the high-energy side. In addition, a broad profile is observed in the red / near-IR border which is attributed to the charge-transfer absorption. Deconvolution of the absorption spectrum into a series of Gaussian bands (see Supporting Information) shows that the introduction of styryl units to JULBD1 strongly shifts the $S_{0} \rightarrow S_{1}$ electronic transition by 144 $\mathrm{nm}$, but the CT band remains mostly unaffected, as compared to the parent unsubstituted julolidyl BODIPY. [7d] It should be mentioned that the use of a julolidyl unit gives a stronger bathochromic shift compared to dimethylamino analogues. ${ }^{[11]}$ The absorption spectrum for JULBD2 when compared to JULBD1 shows an additional bathochromic shift of the main 
transition to $\lambda_{\max }=644 \mathrm{~nm}$, and an additional broadening of the absorption profile due to the CT band (see Supporting Information). The CT character increases when pyridyl and pyridinium substituents are introduced with this effect being most pronounced for the latter. A general bathochromic shift trend in the absorption profile is observed when electron

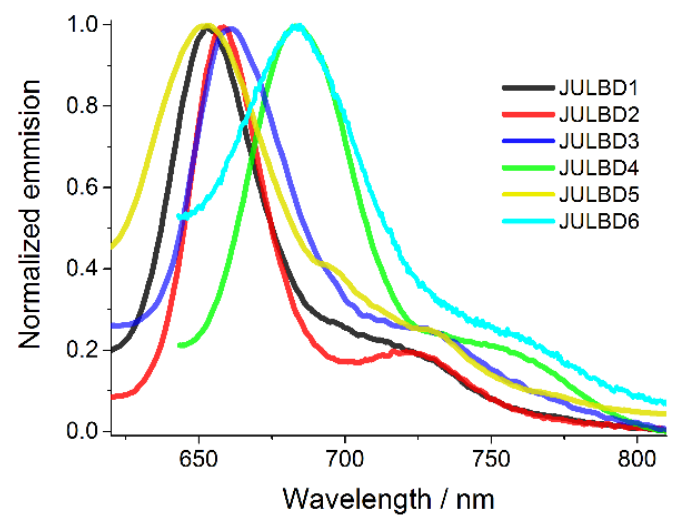

Figure 3. Room temperature emission spectra $(\lambda e x=580 \mathrm{~nm})$ for JULBD16 in DMSO.

withdrawing groups are introduced by increasing the push-pull character of the dyes. The CT-based absorption band becomes more evident in the JULBD3-JULBD6 series, and is red-shifted to $741 \mathrm{~nm}$ (see Supporting Information). A plot of CT transition energy versus the Hammett constant ${ }^{[12]}$ for each substituent is rather tenuous (see Supporting Information). As presented in Table 2 the CT band is higher in energy than the BODIPY localised transition for JULBD1 and JULBD2 but their positions are interchanged for JULBD3 and the energy difference increases to $0.27 \mathrm{eV}$ for JULBD6. For JULBD4 and JULBD6 an additional broad absorption feature is observed in the blue region of the spectrum that is potentially attributed to mostly HOMO and HOMO-1 to LUMO+1 electronic transitions.

The change in the electron withdrawing properties of the vinylaryl-based fragments are more obvious by inspection of the emission spectroscopy results. The room temperature fluorescence spectra for JULBD1-6 in DMSO are shown in Figure 3 with relevant parameters presented in Table 2 . The emission spectrum for JULBD1 consists of a main band at 653 $\mathrm{nm}$ with a smaller broad band on the low-energy side. The emission is gradually red shifted to $684 \mathrm{~nm}$ and the fluorescence quantum yield drops dramatically by 50 fold from 0.21 for JULBD1 to about 0.004 for JULBD6. Figure 4 shows the trend for fluorescence quenching with the corresponding Hammett factor for each substituent. As the electron withdrawing properties of the substituent increase, the CT state becomes lower in energy compared to the locally excited state, so favouring fluorescence quenching via the population of the non-emissive CT state. The fluorescence quenching trend with the increase of the driving force for intramolecular CT is in agreement with electron transfer occurring in the Marcus normal region. ${ }^{[13]}$ The excitation spectra (see Supporting Information) show a similar pattern to the electronic absorption profiles except the missing CT band, thus proving the nonemissive nature of the CT state. The Stokes' shifts for JULBD1-3 are relatively small, but there is an evident increase across the JULBD4-6 series to $1030 \mathrm{~cm}^{-1}$ for JULBD6 which contains the most pronounced charge-transfer character. All compounds were found to be non-fluorescent in the solid state, probably because of the short distance between molecules in the crystal and the resulting cooperative excited-state quenching.

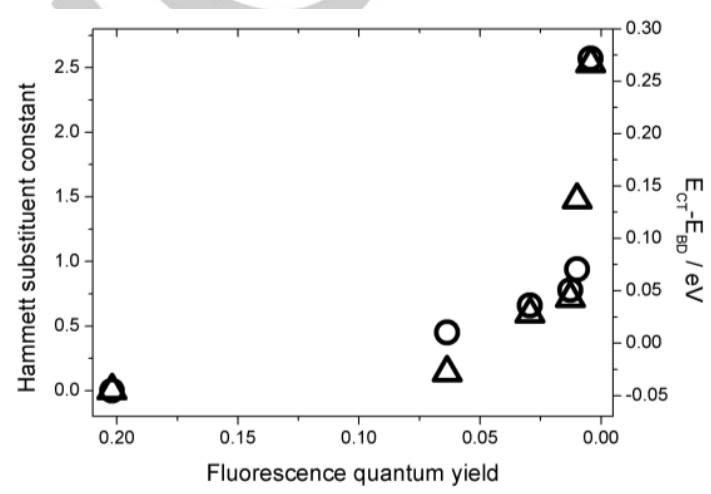

Figure 4. Plot of the fluorescence quantum yield versus the Hammett substituent constant (circles) and the energy difference of the CT and BODIPY-based transitions (triangles).

\section{Molecular Modelling}

In order to understand the nature of the electronic transitions, DFT optimized geometries for compounds JULBD1-6 were calculated. The frontier molecular orbitals (MO) for JULBD1 and JULBD6 are presented in Figure 5 and the diagram of MO energies is presented in Supporting Information. The HOMO-1 is localised on the vinylaryl-BODIPY unit and the HOMO is predominantly localised on the julolidyl moiety. The LUMO is associated with the vinylaryl-BODIPY core so, very crudely, the $\mathrm{HOMO} \rightarrow$ LUMO electronic transition represents julolidyl to vinylaryl-BODIPY charge transfer. The calculated HOMO$1 \rightarrow$ LUMO gap for JULBD1 is $2.31 \mathrm{eV}$, while the predicted $\mathrm{HOMO} \rightarrow$ LUMO gap is $2.15 \mathrm{eV}$, and hence the two bands should overlap $(\Delta \mathrm{E}=0.16 \mathrm{eV})$.

Calculation results performed on the other derivatives revealed somewhat similar frontier orbital diagrams (see Supporting Information) albeit with disparate energies. A general trend of decreasing band gap is observed across the JULBD1-4, 5-6 series. Switching from phenyl to pyridyl substituents results in a drop in LUMO energy and thus the band gap increases. Also, a gradual increase of the HOMO-HOMO-1 gap is observed across the JULBD1-6 series from $0.16 \mathrm{eV}$ to $0.51 \mathrm{eV}$, consistent with the separation trend of the two electronic transitions in the UV-Vis-NIR spectra. The LUMO+1 is well 
separated in energy (> $1 \mathrm{eV}$ ) from the LUMO for JULBD1-3. Two points are worth noting in the case of JULBD4: (i) the LUMO extends well on to the nitro group and (ii) LUMO+1 is separated by only $0.48 \mathrm{eV}$ from the LUMO and is localised almost exclusively on the nitrostyryl unit, therefore the $\mathrm{HOMO} \rightarrow \mathrm{LUMO}+1$ transition represents a pronounced julolidyl to nitrophenyl charge transfer. For compound JULBD5 the HOMO-LUMO gap is larger than that of JULBD1, while the HOMO-HOMO-1 gap is $0.33 \mathrm{eV}$ and increases to $0.51 \mathrm{eV}$ for JULBD6. For the latter the LUMO extends well on to the pyridinium cations which is consistent with a more pronounced charge-transfer character. Once again the LUMO+1 localised on the electron withdrawing substituents is closer to the LUMO so one would expect the HOMO-LUMO+1 transition to appear in the visible region of the spectrum. Interestingly the torsion angle between the julolidyl and BODIPY units gradually decreases across the JULBD1-6 series and this probably contributes to the greater charge transfer character of JULBD6. The Mulliken charge distribution within the molecular dyads JULBD1-6 is consistent with strong ground-state charge transfer (see Supporting Information). The high ground-state dipole moment for the optimised structures is oriented along the B-NJUL axis for JULBD1-5 and in the opposite direction for JULBD6.

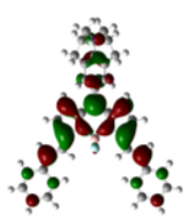

LUMO (-3.19 eV)

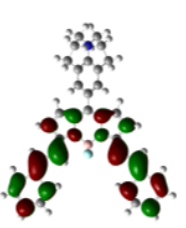

LUMO+1 (-1.84 eV)

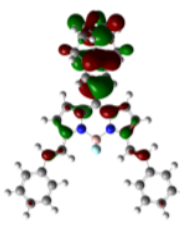

HОMо $(-5.35 \mathrm{eV})$

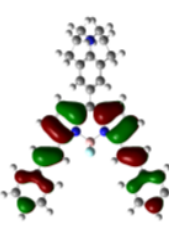

номо-1 $(-5.51 \mathrm{eV})$

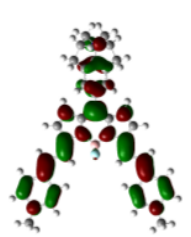

LUMO $(-3.94 \mathrm{eV})$

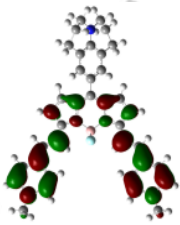

LUMO+1 (-3.15 eV)

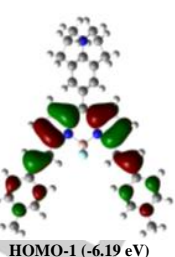

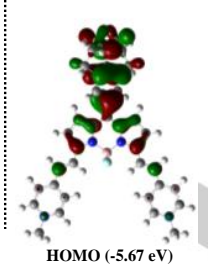

HOMO $(-5.67 \mathrm{eV})$
Figure 5. Representation of the Gaussian calculated Kohn-Sham frontier molecular orbitals for JULBD1 (left) and JULBD6 (right) in DMSO solvent using IEF-PCM model at B3PW91/6-311+G(d,p) theoretical level.

Time-dependent DFT (TD-DFT) calculated electronic absorption spectra are shown in Figure 2 with the relevant parameters in Supporting Information. A general trend of lower predicted energies for $\mathrm{CT}$ transitions and higher energies for the BODIPY localised transitions is observed when compared with experimental data. Although the calculated energy difference between BODIPY and CT transitions is larger than for the experimental data, the decreasing trend in CT band energy relative to the BODIPY transition was well predicted (see Supporting Information). Generally the theoretical absorption profiles match quite well with the experimental results in relation to the shift trends of the bands and the relative position of the electronic transitions. It is worth mentioning that the additional absorption band in the blue region for compounds JULBD4 and JULBD6 is also consistent with the experimental results. While the B3PW91 functional exhibited greater consistency of the BODIPY transition energy with experimental data, the mPW1PW91 functional gave generally better results for $\mathrm{CT}$ transitions and a smaller energy difference between transitions. Thus, the shape of the absorption profile is a better match for the experimental observation when the mPW1PW91/6-311+G(d,p) theoretical level is employed.

\section{Neuronal imaging}

The effectiveness of each of the dyes reported here for neuronal imaging was assessed using the stomatogastric ganglion (STG) of the brown crab Cancer pagurus. The STG is one of the most studied small biological central pattern generator motor systems due to the relatively large size, accessibility and robustness of the neurons located in the STG. All 26 neurons within the STG are known along with their connectivity. The STG contains the well-known central pattern generator neuronal network that produces a pyloric rhythm (PR) that controls the movement of muscles in the foregut of the gastric system of the $\mathrm{crab}^{[14]}$ and involves 11 neurons (1x $A B, I C, V D$ and LP neuron, 2x PD neurons and 5x PY neurons) with a typical cycle frequency of $\sim 1-2 \mathrm{~Hz}$. Optical recording of the STG using VSDs has been well-studied, ${ }^{[15]}$ allowing the simultaneous recording of the electrical activity of many cells.

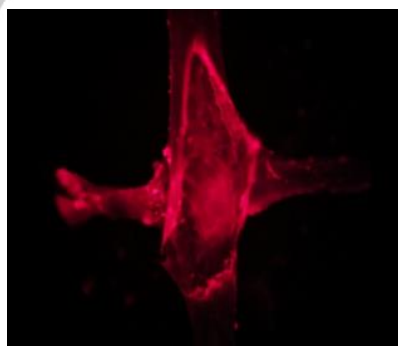

(b) JULBD1

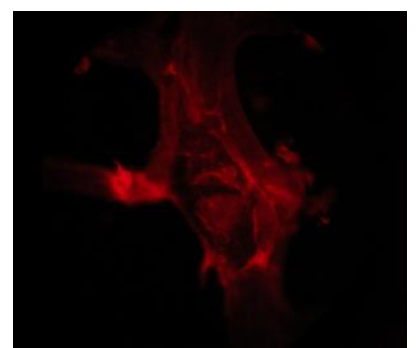

(c) JULBD2
Figure 6. Fluorescence images of the STG of $C$. pagurus after bath application of JULBD1 (a) and JULBD2 (b) investigated here.

For each experiment, the preparation was dissected and the dye bath was applied for 20 minutes, followed by a 20-minute washout period. Recording was initiated immediately after the washout period was complete. All of the dyes were applied at $10^{-4} \mathrm{M}$ with the exception of JULBD2 and JULBD5 which were too toxic at this concentration (indicated by the lack of extracellular neural activity) and therefore applied at $10^{-5} \mathrm{M}$. 
Figure 6 shows an example of an STG after BODIPY dyes had been bath applied. Comparison of the fluorescence images shows that some of the new BOPIDY dyes show good fluorescence properties, in particular JULBD1-4 where the dyed neuropil and individual neurons can be clearly seen (see Supporting Information). There is some staining of the neuropil and cell membranes when using JULBD5, but very little fluorescence is achieved when using JULBD6. One can relate the decrease of the fluorescence staining with the quantum yield decrease in the JULBD1-6 series. It should be noted that strong fluorescence signal is not necessarily a requirement for VSDs but it is the intensity modulation which allows for sensing of membrane potential changes. While good fluorescence is useful and indeed desirable in order to observe the STG under the microscope, low fluorescence may not necessarily result in a poor SNR where, in fact, the opposite could be true if the change in fluorescence response to neural activity is large compared to the low-level baseline fluorescence.

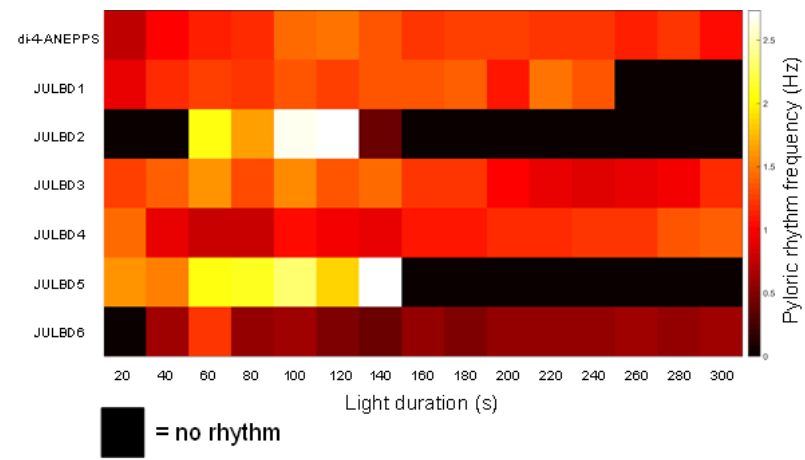

Figure 7. The toxicity of each novel BOPIDY-based dye as measured by a change in the PR frequency $(\mathrm{Hz})$ compared with di-4-ANEPPS over a variety of fluorescence durations.

The toxicity of each dye was assessed by calculating the change in frequency of the PR measured at the Ivn nerve of the preparation where one cycle was defined as the duration of between the onset of an LP neuron burst and the next LP neuron burst, similar to Pruess and Stein. ${ }^{[16]}$ For each dye, the STG was illuminated with appropriate light for increments of 20 s, starting from $20 \mathrm{~s}$ to 300 s and the PR frequency calculated. As Figure 7 shows, the toxicity of each dye varies. As di-4-ANEPPS is widely used, it is not surprising that it has a suitably low toxicity, as shown by the small change in the PR frequency for each light duration increment $(N=5)$. In comparison, JULBD previously reported by our group ${ }^{[7]}$ soon killed the preparation after 100 seconds of fluorescent light exposure, indicated by the lack of PR $(N=1)$. A similar effect can be seen with JULBD2 and JULBD5 $(\mathrm{N}=1$ and 2 respectively), which cause a more pronounced increase in $\mathrm{PR}$ frequency prior to the death of the preparation, despite lower concentrations of $10^{-5} \mathrm{M}$ that were applied in the case of these two dyes. Figure 8 shows that JULBD1,3,4,6 $(N=1)$ have potentially promising results in terms of toxicity, where the PR remains around $1 \mathrm{~Hz}$, similar to that of di-4-ANEPPS. It can be concluded that the introduction of substituents in $\beta$-position reduces the toxicity of BODIPY dyes, with the exception of JULBD2 and JULBD5. Pyridine and carboxylic acid are both strong coordinating units and this could be argued to cause their higher toxicity.

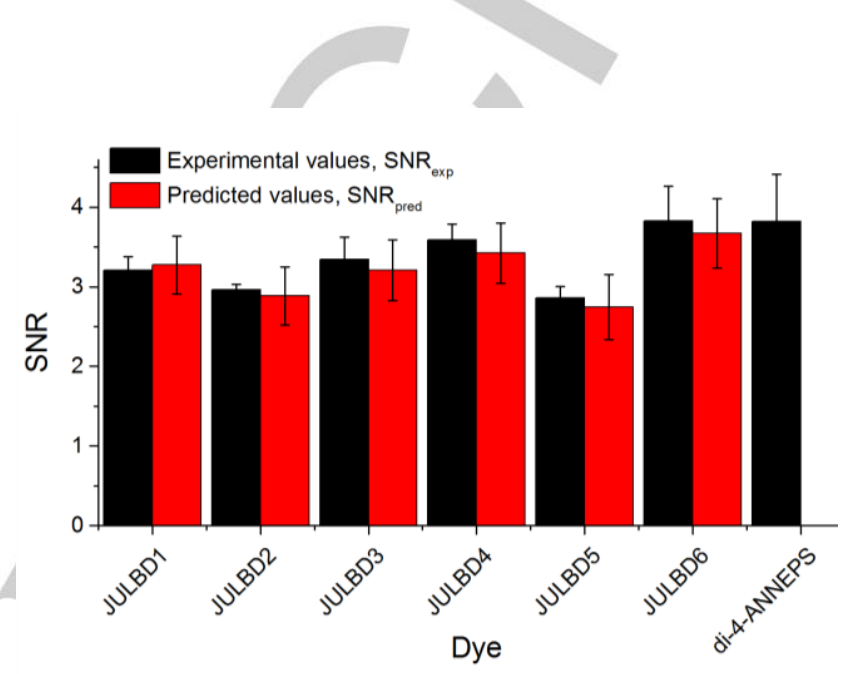

Figure 8. The SNR of each dye compared with commercial di-4-ANEPPS.
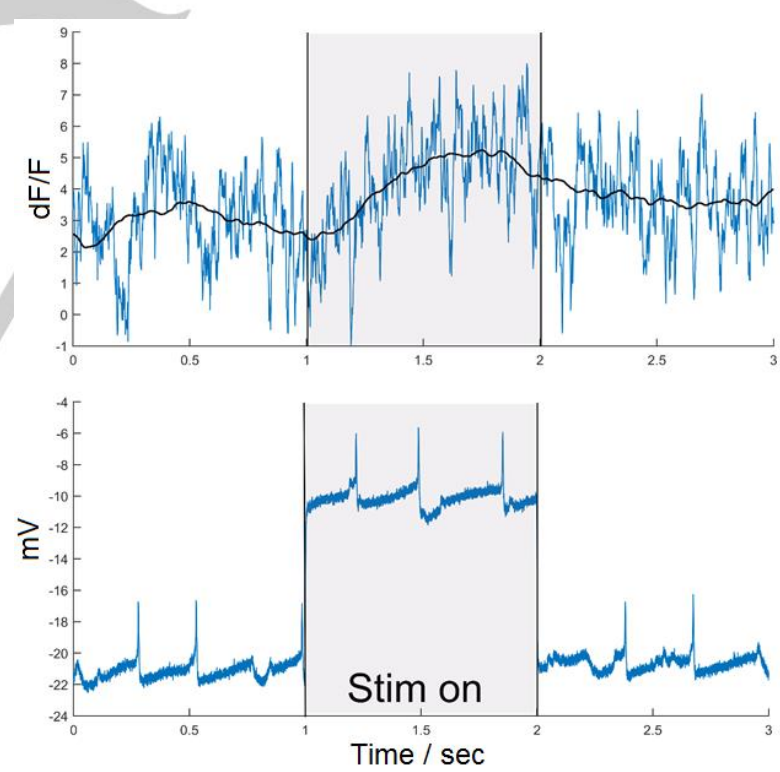

Figure 9. Raw (blue) and averaged (black) optical VSD (top) and corresponding intracellular recording (bottom) for JULBD6. The effect of the current injection, as indicated by the shaded area, into the recorded cell can be clearly seen in the optical data for both VSDs, while the effect on the cell membrane voltage can be seen in the bottom plots.

To further assess the change in fluorescence of the dyes for neuronal imaging, the signal-to-noise ratio (SNR) for each dye 
was calculated, again using di-4-ANEPPS as the benchmark. These experiments involved the injection of a $0.1 \mathrm{nA}$ current into a neuron while excitation light was applied for 32 seconds and the fluorescent activity imaged. As shown in the Figure 8, BODIPY dyes JULBD1-5 offer only slightly lower SNR values to di-4ANEPPS. The superior SNR of JULBD6 is somehow surprising given the poor staining. Figure 9 shows a representative example of the optical recording and the corresponding intracellular cell membrane voltage recording for JULBD6 when injecting a chosen cell with $0.1 \mathrm{nA}$ of current. This data shows a clear correlation between the optical signal and the intracellular data where action potentials match increases in fluorescence in many cases, and the current injection results in an increase in the membrane voltage potential and the optical signal at very similar time-scales. When compared to the first generation of BODIPY VSDs, ${ }^{[7 e]}$ dyes presented in this work show at least a three-fold increase in SNR. This can be attributed to both a higher sensitivity to membrane potential changes but also a better light penetration in the red region of the spectrum. These results indicate that BODIPY dyes are a promising alternative VSD to di-4-ANEPPS when recording the activity of multiple neurons.

Two possible mechanisms could be considered by which neuronal membrane potential changes can result in fluorescence signal modulation. Change of the BODIPY and CT transition energies from interaction of the dipole moments of the respective states with the external electric field can shift the absorption / fluorescence spectra out of the filters window, while the change in the relative position of the two excited states will affect the electron transfer driving force and the fluorescence quantum yield It could be argued that in line with the first pathway, the drop in SNR for JULBD5 might be a result of the blue-shifted absorption profile as compared to JULBD1-4,6 analogues. The improved signal for JULBD6 is possibly also a result of the better dye alignment parallel to the membrane potential as result of hydrophilic pyridinium cations acting as anchoring groups. What is evident is that the voltage sensing by BODIPY dyes occurs differently compared to ANEPPS dyes as fluorescence occurs from the CT state in the latter, while for JULBD1-6 emission occurs primarily from the locally excited BODIPY unit.

In an attempt to quantify the above mentioned structure-property relationships the experimental data were analysed using linear regression models. The dependent variable used was the calculated average SNR for each dye and the independent variables being the fluorescence quantum yield, $\Phi_{\mathrm{f}}$, ground state dipole moment, $\mu_{\mathrm{GS}}, \mathrm{BD}$ and $\mathrm{CT}$ transitions energy, $\mathrm{E}_{\mathrm{BD}}$ and $\mathrm{E}_{\mathrm{CT}}$, or their difference, $\Delta \mathrm{E}$. Equation 1 represents a conjectural dependence of SNRpred with $\Phi f, \mu_{\mathrm{GS}}, \mathrm{E}_{\mathrm{BD}}$ and $\Delta \mathrm{E}$. Even though there we are not aware of an arguable scientific explanation ${ }^{[17]}$ of Eq. 1 it is immediately obvious that the two major component in the $S_{N R}$ pred relationship are the transition energy gap and the energy of the $B D$ transition. Setting $E_{B D}$ and $E_{C T}$ as two separate variables, or excluding $\mathrm{E}_{\mathrm{BD}}$ gives less accurate models suggesting that the relative position of the $\mathrm{CT}$ and $\mathrm{BD}$ absorption bands is more important compared to the absolute value of the CT transition energy. The general redshift of the spectrum along with increasing the driving force for the charge transfer from the LES seems to be the way of improving the SNR of the BODIPY voltage-sensing dyes.

$$
S N R_{\text {pred }}=2.332 \Delta E-2.906 E_{B D}+0.078 \Phi_{\mathrm{f}}+0.072 \mu_{G S}+
$$

This SNR relationship between the basic photophysics of the BODIPYs and their potentiometric response affords for the first time a predictive tool for improving VSDs.

\section{Conclusions}

This work introduces a real viable alternative to the cyanine-based voltage sensitive dyes based on the BODIPY subunit. In addition the optical response is pushed out to the far-red and near infrared region (NIR) which offers advantages over simple VSDs. The stomatogastric ganglion of the brown crab (C. pagurus) offers a good model to measure both toxicity and change in fluorescence, as indicated by the signal to noise ratio, for the new VSDs. The toxicity of most dyes is acceptable and comparable to the widely used VSD, di-4-ANEPPS, with one exception which disrupts the pyloric rhythm of the STG to the point where neural activity no longer exists soon after the dye is applied. The majority of dyes also offer comparable SNR values as di-4-ANEPPS and show similar changes in fluorescence that correlate well with changes in neuronal membrane potentials.

While the julolidyl unit gives rise to a strongly red-shifted CT absorption, the $\pi$-extension in the $\beta$-position brings the localised $\pi-\pi^{*}$ and CT electronic transitions closer together in energy. In addition, the lack of bulky substituents on the dipyrromethene subunit proximal to the julolidyl (i.e., 1,7 positions) is also significant in the molecular design. The minimisation of steric hindrance permits the julolidyl group to twist to the optimum geometry to facilitate through-bond electronic communication. The overall molecular design also offers a straightforward approach to finely tune the position of the charge transfer state relative to the BODIPY $S_{1}$ state, so that the interplay of the two excited states controls the fluorescence of the chromophore, thus allowing for sensing of changes in the environment (i.e., electric field). These results clearly show the potential that BODIPY dyes have for the large-scale imaging of neuronal networks. Future work is involved in the design and preparation of next generation BOPIDY-derived VSDs, by DFT-guided tuning of the CT and BD excited states energy and application of the hypothesised structure-property relationship. The aim is to produce enhanced responsive dyes ${ }^{[18]}$ for their use in monitoring neuronal activity in STG and, ultimately, mammalian tissue for applications such as the study of diseases 


\section{Experimental Section}

\author{
Structural characterisation
}

${ }^{1} \mathrm{H}-,{ }^{13} \mathrm{C}$ - and DEPT-135 ${ }^{\circ} \mathrm{NMR}$ spectra, as well as two-dimensional homo$\left({ }^{1} \mathrm{H} /{ }^{1} \mathrm{H}\right.$ COSY $\left.-45^{\circ}\right)$ and heteronuclear $\left({ }^{1} \mathrm{H} /{ }^{13} \mathrm{C} \mathrm{HMQC}\right.$ and $\left.\mathrm{HMBC}\right)$ correlation spectra were recorded with a Jeol ECS $400 \mathrm{MHz}$ and a Bruker $700 \mathrm{MHz}$ spectrometers. Chemical shifts for ${ }^{1} \mathrm{H}$ - and ${ }^{13} \mathrm{C}-\mathrm{NMR}$ spectra are referenced relative to the residual protiated solvent. ${ }^{11} \mathrm{~B}-\mathrm{NMR}$ spectra are referenced relative to $\mathrm{BF}_{3} \cdot \mathrm{OEt} 2 .{ }^{19} \mathrm{~F}-\mathrm{NMR}$ spectra are referenced relative to $\mathrm{CFCl}_{3}$. Electronic absorption spectra were recorded at $\mathrm{RT}$ using a Shimadzu UV-1800 spectrophotometer. Fluorescence emission spectra were acquired at RT with Shimadzu RF-6000 fluorimeter.

All crystal structure data were collected on an Xcalibur, Atlas, Gemini Ultra diffractometer equipped with an Enhance Ultra $(\mathrm{Cu}) \mathrm{X}$-ray Source $(\lambda \mathrm{CuKa}$ $=1.54184 \AA$ ) and an Oxford Cryosystems CryostreamPlus open-flow N2 cooling device. Cell refinement, data collection and data reduction were undertaken via the CrysAlisPro[19] software. Intensities were corrected for absorption empirically using spherical harmonics. The structures were solved using $X^{[20]}$ and refined using $\mathrm{XL}^{[21]}$ through the Olex2 interface. ${ }^{[22]}$ All non-hydrogen atoms were refined with anisotropic displacements and hydrogen atoms were positioned with idealised geometry and constrained using a riding model.

\section{Molecular modelling}

In order to estimate the energies of BODIPY based and CT absorptions the spectrum profile in the red region was deconvoluted into four peaks with the PeakFit software. Three peaks were set to have the same fullwidth at half-maximum while the width of the fourth peak modelling the CT band was left independent. The fitted CT band was always about four times broader than the BODIPY-based transitions.

Energy-minimised structures of JULBD1-6 were calculated in Gaussian $09^{[23]}$ in order to describe and compare the frontier molecular orbitals. Firstly, the structure of JULBD3 was optimised with the DFT B3LYP/3-21G method and the result was used as the input for calculations at the B3LYP/6-311+G(d,p), B3LYP/LanL2DZ, B3PW91/6-311+G(d,p) and B3PW91/LanL2DZ theoretical levels without any symmetry constraint in the gas phase. The results were compared with the $\mathrm{X}$-ray crystal structures. The B3LYP functional returned generally longer B-F and N-B bonds compared to B3PW91 and the B3PW91/6-311+G(d,p) optimization method was selected for further calculations. The optimised geometries were further used as input for calculations in DMSO solvent using IEFPCM and the same theoretical level. The UV-Vis-NIR absorption spectra of compounds JULBD1-6 in DMSO were calculated using IEF-PCM solvent model at B3PW91/6-311+G(d,p) TD-DFT theory level, and their images were obtained by using 0.1 and $0.2 \mathrm{eV}$ half-widths at half-height for the BODIPY and CT transitions, respectively.

\section{Dissection}

Adult Cancer Pagurus were obtained from Hodgkinson Fresh Fish (Smithfield Market, Manchester, UK). Crabs were housed in tanks with artificial sea water at $10-14^{\circ} \mathrm{C}$ (salt content $\sim 1.025 \mathrm{~g} / \mathrm{cm}^{3}$ ) made from artificial sea salt (Reefsalt, AquaMed). Crabs were dissected according to Gutierrez and Grashow, ${ }^{24]}$ with the STNS pinned down in a silicone elastomer-lined (ELASTOSIL RT-601, Wacker, Munich, Germany) Petri dish in saline consisting of (mmol/L): $\mathrm{NaCl}, 440 ; \mathrm{MgCl} 2 \cdot 6 \mathrm{H} 20,26$; $\mathrm{CaCl}_{2} \cdot 2 \mathrm{H}_{2} \mathrm{O}, 13 ; \mathrm{KCl}, 11$; trizma base, 10 ; maleic acid, 5 . The saline was kept between $10-15^{\circ} \mathrm{C}$ and had a $\mathrm{pH}$ of $7.2-7.5$. All experiments were carried out in accordance with the European Communities Council Directive of 25th November 1986 (86/609/EEC).

\section{Preparation and application of the dyes}

For each of the dyes, a stock solution was created by mixing the dye with $1 \mathrm{ml} 20 \% \mathrm{~F}-127$ pluronic acid DMSO solution (Invitrogen, Paisley, UK). All stock solutions were kept at room temperature in the dark. 4-(2-(6(Dibutylamino-2-naphthalenyethenyl)-1-(3-sulfopropyl)pyridinium hydroxide (Di-4-ANEPPS, Cambridge Bioscience, Cambridge, UK) was used as a benchmark for comparison against the novel dyes reported here. On the day of recording, the stock solution of each dye were diluted to 10$4 \mathrm{M}$, unless otherwise stated, in saline and bath applied to the desheathed STG for 20 minutes in the dark at $5^{\circ} \mathrm{C}$. After 20 minutes, the dye was washed off for a further 20 minutes ( 2 changes of saline and followed by a rest period of 10 minutes at $5^{\circ} \mathrm{C}$ ).

\section{Intracellular and extracellular recording}

Electrophysiology was performed following Hedrich et al., ${ }^{[25]}$ whereby the STG was pinned and desheathed to facilitate intracellular recording and the penetration of the dyes used in this study. For extracellular recordings the Ivn was isolated from the rest of the preparation bath using petroleum jelly to form a well. One of two stainless steel electrodes was inserted into this well, while a reference electrode was placed outside of the well in the petri dish to create a differential signal between the two electrodes. This signal was filtered and amplified with an AC differential amplifier (AM Systems Model 1700, Sequim, WA). For intracellular recordings glass electrodes (TW120F-3, World Precision Instruments, Aston, Stevenage, UK; 25-40 M $\Omega$ ) were pulled using a P97 puller (Heat: 514, Pull: 130, Velocity: 80 , Time: 150, $\mathrm{P}=500$; Sutter Instruments, CA, USA) and filled with $3 \mathrm{M} \mathrm{KCl}$ solution. Signals were amplified using an IE-251A Amplifier (Warner Instruments Corporation, Hamden, CT). Both intracellular and extracellular signals were recorded and analysed using a Micro 1401-3 signal processing device (CED, Cambridge, UK) and Spike 2 software (CED, Cambridge, UK).

\section{Intracellular current injection}

For each intracellular neuronal stimulation, 5 sets of $10 \times 0.1 \mathrm{nA}$ pulses were injected into a selected cell for a duration of 1 second, with a 2 second gap between each pulse and a 1 minute gap between each set of pulses. Current injections were generated and controlled using Spike2 software and a Micro 1401-3 signal processing device (CED, Cambridge, UK). During the current injection procedure, fluorescent light was applied and the optical activity of each neuron recorded using a MiCAM 02 imaging system (SciMedia Ltd., Tokyo, Japan).

\section{Imaging of fluorescence}

Throughout fluorescence imaging a MiCAM 02 imaging system (SciMedia Ltd., Tokyo, Japan) was used along with a high resolution camera $(6.4 \mathrm{~mm}$ x $4.8 \mathrm{~mm}$ actual sensor chip size). A 10x objective (UMPLFL10XW, NA 0.30, WD $3.30 \mathrm{~mm}$, Olympus Corporation, Tokyo, Japan) was mounted on a BX51 WI fluorescence microscope (Olympus Corporation, Tokyo, Japan). For the toxicity experiments, the spatial resolution was set at 48 $x 32$ pixels and the temporal resolution varied from $1.3 \mathrm{~ms}$ to $13.7 \mathrm{~ms}$ in order to set the desired time for the imaging recording session (starting at 20 s to 300 s using increments of 20 s light exposure). At the end of the illumination, the light was turned off for a period of time to allow the preparation to recover to baseline levels. During the SNR experiments, the spatial resolution was the same as used in the toxicity experiments and the temporal resolution was set at $1.5 \mathrm{~ms}$, resulting in a $32 \mathrm{~s}$ recording 
period. Illumination was provided by a $150 \mathrm{~W}$ ultra-low ripple halogen light source (HL-151, Moritex Corporation Tokyo, Japan) with a shutter controlled from a computer using BrainVision software (SciMedia Ltd., Tokyo, Japan). For the di-4-ANEPPS experiments a wide green filter cube was used (BP 480-550 excitation filter, LP 590 emission filter, Olympus Corporation, Tokyo, Japan), while a wide orange filter cube (ET620/60x excitation filter, ET700/75m emission filter, Chroma Technology Corp, Vermont, USA) was used for the novel dyes presented in this study. To reduce mechanical noise, the microscope was placed on an anti-vibration table (630500 series, Technical Manufacturing Corporation, Peabody, MA, USA).

\section{Data analysis and visualisation}

For analysis of the fluorescence imaging data BrainVision software (SciMedia Ltd., Tokyo, Japan) was used. For the calculation of the SNR reported the fluorescence data for each of the 5 sets of 10 current injections (30 seconds in length) for each cell during the current injection (1 sec duration) and between injections (2 sec duration) was averaged using Spike2 (CED, Cambridge, UK). Prior to averaging, baseline drifts due to thermal changes in the light source and slow frequency components of the signal were removed using the DC-remove function in Spike2 (using a time constant of 3 secs, CED, Cambridge, UK). The SNR was calculated as follows:

$$
S N R=\sum_{i=1}^{N} \frac{\mu C I_{i}}{\sigma \varepsilon_{i}}
$$

where $\mathrm{i}$ is the index of the $\mathrm{i}$-th neuron, $\mathrm{N}$ is the total number of neurons, $\mu \mathrm{Cli}$ is the mean of the fluorescence signal during each current injection (50 in total) and $\sigma \varepsilon i$ is the standard deviation of the average fluorescence signal considering the periods (50 in total) when no current injection was applied to the cell. The toxicity of each dye was measured by the change in the frequency $(\mathrm{Hz})$ of the pyloric rhythm where the length of each pyloric cycle was defined as the duration between the onset of an LP neuron burst and the onset of the next LP neuron burst. The frequency was calculated using custom scripts written in Spike2 (CED, Cambridge, UK). Final plots were created using GraphPad Prism (GraphPad Software, CA, USA) and Matlab (Mathworks, MA, USA). The data analysis for the derivation of the linear regression model was done using the SPSS software (IBM Corp., Armonk, NY, USA).

\section{Synthesis}

All chemicals were purchased from commercial sources and used as received unless otherwise stated. Basic solvents for synthesis were dried using typical literature methods. Solvents for spectroscopic investigations were of the highest purity available. The starting material 3,5-dimethyl-8julolidyl BODIPY (1) was prepared by using the method previously reported by our group. ${ }^{[7]}$

\section{Preparation of 3,5-distyryl-8-julolidyl BODIPY (JULBD1)}

Benzaldehyde ( $51 \mu \mathrm{L}, 0.5 \mathrm{mmol}, 4$ eq.), piperidine $(0.25 \mathrm{~mL}, 20$ eq.) and glacial acetic acid $(0.14 \mathrm{~mL}, 20$ eq.) were added to a solution of $1(49 \mathrm{mg}$, $0.125 \mathrm{mmol})$ in anhydrous $\mathrm{CH}_{3} \mathrm{CN}(8 \mathrm{~mL})$ containing $4 \AA$ molecular sieves $(1 \mathrm{~g})$. The resulting mixture was refluxed until the complete consumption of the starting material $(1.5 \mathrm{~h})$. The solution was filtered, DCM and $\mathrm{Et}_{2} \mathrm{O}$ (1:5) were added, and the mixture was washed with $0.05 \mathrm{M} \mathrm{HCl}$, saturated aqueous $\mathrm{NaHCO}_{3}$ and water. The solvent was removed to give a dark purple solid which was washed with hexane and dried under vacuum (50 $\mathrm{mg}, 70 \%$ yield). ${ }^{1} \mathrm{H}$ NMR $\left(700 \mathrm{MHz}, \mathrm{CDCl}_{3}\right): \delta(\mathrm{ppm})=7.80$ (d, $J=16.3$ $\mathrm{Hz}, 2 \mathrm{H}$, trans $\mathrm{CH}=\mathrm{CH}), 7.65(\mathrm{~d}, J=7.5 \mathrm{~Hz}, 4 \mathrm{H}, \mathrm{o}-\mathrm{Ph}$ ), 7.41 (ps t, $J=7.7$ $\mathrm{Hz}, 4 \mathrm{H}, \mathrm{m}-\mathrm{Ph}), 7.34-7.28(\mathrm{~m}, 4 \mathrm{H}$, trans $\mathrm{CH}=\mathrm{CH}+\mathrm{CH}$ p-Ph), $7.04(\mathrm{~s}, 2 \mathrm{H}$,
PhJul), 6.98 (d, $J=4.3 \mathrm{~Hz}, 2 \mathrm{H}, \beta$-pyrrole), 6.93 (d, $J=4.4 \mathrm{~Hz}, 2 \mathrm{H}, \beta$ pyrrole), 3.29 (t, $J=5.7 \mathrm{~Hz} 4 \mathrm{H}, \mathrm{CH}_{2} \mathrm{Jul}$ ), $2.82\left(\mathrm{t}, J=6.3 \mathrm{~Hz}, 4 \mathrm{H}, \mathrm{CH}_{2} \mathrm{Jul}\right.$ ), 2.06-1.98 (m, 4H, CH $\mathrm{Jul}^{2}{ }^{13} \mathrm{C} \mathrm{NMR}\left(176 \mathrm{MHz}, \mathrm{CDCl}_{3}\right): \delta(\mathrm{ppm})=152.86$, $145.11,141.85,136.93,135.89,135.21,130.43,129.47,128.89,128.82$ $127.58,121.62,120.89,119.94,115.43,50.11,27.92,21.72 .{ }^{11} \mathrm{~B}$ NMR $(96$ $\left.\mathrm{MHz}, \mathrm{CDCl}_{3}\right): \delta(\mathrm{ppm})=1.31(\mathrm{t}, J=33.1 \mathrm{~Hz}) \cdot{ }^{19} \mathrm{~F} \mathrm{NMR}\left(282 \mathrm{MHz}, \mathrm{CDCl}_{3}\right)$ : $\delta(\mathrm{ppm})=-139.5(\mathrm{q}, J=33.1 \mathrm{~Hz})$. NSI-FTMS $(\mathrm{m} / \mathrm{z})$ : found $[\mathrm{M}]^{+}$567.2657, $[\mathrm{M}+\mathrm{H}]^{+}$568.2711, calcd. for $\mathrm{C}_{3} \mathrm{H}_{32} \mathrm{BF}_{2} \mathrm{~N}_{3}$ : 567.2652, $\mathrm{C}_{37} \mathrm{H}_{33} \mathrm{BF}_{2} \mathrm{~N}_{3}$ : 568.2737 .

\section{Preparation of 3,5-di(4-carboxystyryl)-8-julolidyl BODIPY (JULBD2)}

4-Formylbenzoic acid ( $112 \mathrm{mg}, 0.75 \mathrm{mmol}, 6$ eq.), piperidine $(0.25 \mathrm{~mL}, 20$ eq.) and glacial acetic acid ( $0.14 \mathrm{~mL}, 20$ eq.) were added to a solution of 1 (49 mg, $0.125 \mathrm{mmol})$ in anhydrous $\mathrm{CH}_{3} \mathrm{CN}(8 \mathrm{~mL})$ containing $4 \AA$ molecular sieves $(1 \mathrm{~g})$. The resulting mixture was refluxed until the complete consumption of the starting material $(2 \mathrm{~h})$. $\mathrm{MeOH}(5 \mathrm{~mL})$ was added to fully dissolve the precipitate formed. The solution was filtered, $\mathrm{DCM}$ and $\mathrm{Et}_{2} \mathrm{O}$ (1:5) were added and the product extracted with saturated aqueous $\mathrm{NaHCO}_{3}$. The combined aqueous layer was acidified with $1 \mathrm{M}$ $\mathrm{HCl}$ to $\mathrm{pH}=6$ to give a dark purple solid. The product was recrystallized by precipitating from DMSO solution with $0.5 \mathrm{M} \mathrm{HCl}$. The collected solid was washed with $0.02 \mathrm{M} \mathrm{HCl}$, water and $\mathrm{Et}_{2} \mathrm{O}$ and dried under vacuum (45 $\mathrm{mg}, 44 \%$ yield). A clear DMSO signal at $2.54 \mathrm{ppm}$ in the ${ }^{1} \mathrm{H}$-NMR spectrum suggests inclusion of two DMSO molecule per BODIPY in the crystalline structure. ${ }^{1} \mathrm{H}$ NMR $\left(700 \mathrm{MHz}\right.$, DMSO-d $\left.\mathrm{d}_{6}\right): \delta(\mathrm{ppm})=13.01\left(\mathrm{~s}, 2 \mathrm{H}, \mathrm{CO}_{2} \mathrm{H}\right)$, $8.02(\mathrm{~d}, J=8.3 \mathrm{~Hz}, 4 \mathrm{H}, \mathrm{Ph}), 7.74$ (d, $J=8.3 \mathrm{~Hz}, 4 \mathrm{H}, \mathrm{Ph}$ ), 7.69 (br s, 4H, $\mathrm{CH}=\mathrm{CH}), 7.30(\mathrm{~d}, J=4.5 \mathrm{~Hz}, 2 \mathrm{H}, \beta$-pyrrole), $7.11(\mathrm{~m}, 4 \mathrm{H}, \beta$-pyrrole + PhJul), $3.3-3.33$ (overlapped with water peak, $4 \mathrm{H}, \mathrm{CH}_{2} \mathrm{Jul}$ ), 2.79 (t, $J=$ $\left.6.3 \mathrm{~Hz}, 4 \mathrm{H}, \mathrm{CH}_{2} \mathrm{Jul}\right), 1.93$ (m, 4H, CH $\mathrm{CH}_{2}$ Jul). ${ }^{13} \mathrm{C} \mathrm{NMR}(176 \mathrm{MHz}$, DMSO $\left.\mathrm{d}_{6}\right): \delta(\mathrm{ppm})=166.94,151.06,145.64,141.87,140.38,134.97,134.36$, $130.73,130.43,130.09,129.60,127.00,120.83,120.64,120.07,116.74$, 49.33, 27.08, 20.87. ${ }^{11} \mathrm{~B}$ NMR (96 MHz, DMSO-d 6 ): $\delta(\mathrm{ppm})=1.19$ (br t, $J$ $=30.6 \mathrm{~Hz}) \cdot{ }^{19} \mathrm{~F} \mathrm{NMR}\left(282 \mathrm{MHz}, \mathrm{CDCl}_{3}\right): \delta(\mathrm{ppm})=-136.6(\mathrm{br} \mathrm{q}, J=30.5$ $\mathrm{Hz})$. NSI-FTMS (m/z): found $[\mathrm{M}-\mathrm{H}]^{-}$654.2374, $[\mathrm{M}-2 \mathrm{H}]^{2-} 326.6154$, calcd. for $\mathrm{C}_{39} \mathrm{H}_{31} \mathrm{BF}_{2} \mathrm{~N}_{3} \mathrm{O}_{4}: 654.2388, \mathrm{C}_{39} \mathrm{H}_{30} \mathrm{BF}_{2} \mathrm{~N}_{3} \mathrm{O}_{4}: 326.6155$.

\section{Preparation of 3,5-di(4-cyanostyryl)-8-julolidyl BODIPY (JULBD3)}

4-Cyanobenzaldehyde ( $98 \mathrm{mg}, 0.75 \mathrm{mmol}, 6$ eq.), piperidine $(0.25 \mathrm{~mL}, 20$ eq.) and glacial acetic acid ( $0.14 \mathrm{~mL}, 20$ eq.) were added to a solution of 1 (49 mg, $0.125 \mathrm{mmol})$ in anhydrous $\mathrm{CH}_{3} \mathrm{CN}(8 \mathrm{~mL})$ containing $4 \AA$ molecular sieves $(1 \mathrm{~g})$. The resulting mixture was refluxed until the complete consumption of the starting material $(18 \mathrm{~h})$. The solution was filtered, $\mathrm{DCM}$ and $\mathrm{Et}_{2} \mathrm{O}$ (1:5) were added, and the mixture was washed with $0.05 \mathrm{M} \mathrm{HCl}$, saturated aqueous $\mathrm{NaHCO}_{3}$ and water. The solvent was removed to give a black solid which was purified by flash chromatography on silica gel (DCM eluent). The solvent was removed to give the desired product as a dark purple solid (10 mg, $13 \%$ yield). ${ }^{1} \mathrm{H}$ NMR $(700 \mathrm{MHz}$, $\left.\mathrm{CDCl}_{3}\right): \delta(\mathrm{ppm})=7.86(\mathrm{~d}, J=16.3 \mathrm{~Hz}, 2 \mathrm{H}$, trans $\mathrm{CH}=\mathrm{CH}), 7.69(\mathrm{ps} \mathrm{q}, J=$ $8.4 \mathrm{~Hz}, 8 \mathrm{H}, 0-\mathrm{Ph}+\mathrm{m}-\mathrm{Ph}), 7.25(\mathrm{~d}, J=16.3 \mathrm{~Hz}, 2 \mathrm{H}$, trans $\mathrm{CH}=\mathrm{CH}$, overlapped with $\mathrm{CHCl}_{3}$ peak), 7.06 (s, 2H, PhJul), $7.04(\mathrm{~d}, J=4.3 \mathrm{~Hz}, 2 \mathrm{H}$, $\beta$-pyrrole), 6.96 (d, $J=4.4 \mathrm{~Hz}, 2 \mathrm{H}, \beta$-pyrrole), $3.36-3.29$ ( $\mathrm{m}, 4 \mathrm{H}, \mathrm{CH}_{2} \mathrm{Jul}$ ), $2.82\left(\mathrm{t}, J=6.2 \mathrm{~Hz}, 4 \mathrm{H}, \mathrm{CH}_{2} \mathrm{Jul}\right), 2.07-1.99\left(\mathrm{~m}, 4 \mathrm{H}, \mathrm{CH}_{2} \mathrm{Jul}\right) .{ }^{13} \mathrm{C} \mathrm{NMR}$ $\left(176 \mathrm{MHz}, \mathrm{CDCl}_{3}\right): \delta(\mathrm{ppm})=151.59,145.71,143.34,141.23,136.36$ $132.70,132.68,130.76,129.93,127.75,123.09,121.31,121.05,119.09$ $116.06,111.57,50.15,27.94,21.61 .{ }^{11} \mathrm{~B} \mathrm{NMR}\left(96 \mathrm{MHz}, \mathrm{CDCl}_{3}\right): \delta(\mathrm{ppm})$ $=1.24(\mathrm{t}, J=33.2 \mathrm{~Hz}) .{ }^{19} \mathrm{~F} \mathrm{NMR}\left(282 \mathrm{MHz}, \mathrm{CDCl}_{3}\right): \delta(\mathrm{ppm})=-138.6(\mathrm{q}, J$ $=33.3 \mathrm{~Hz})$. NSI-FTMS (m/z): found $[\mathrm{M}]^{+}$617.2547, $[\mathrm{M}+\mathrm{H}]^{+}$618.2618, calcd. for $\mathrm{C}_{39} \mathrm{H}_{30} \mathrm{BF}_{2} \mathrm{~N}_{5}$ : 617.2564, $\mathrm{C}_{39} \mathrm{H}_{31} \mathrm{BF}_{2} \mathrm{~N}_{5}: 618.2642$. 


\section{Preparation of 3,5-di(4-nitrostyryl)-8-julolidyl BODIPY (JULBD4)}

4-Nitrobenzaldehyde (113 mg, $0.75 \mathrm{mmol}, 6$ eq.), piperidine $(0.25 \mathrm{~mL}, 20$ eq.) and glacial acetic acid $(0.14 \mathrm{~mL}, 20$ eq.) were added to a solution of 1 (49 mg, $0.125 \mathrm{mmol})$ in anhydrous $\mathrm{CH}_{3} \mathrm{CN}(8 \mathrm{~mL})$ containing $4 \AA$ molecular sieves $(1 \mathrm{~g})$. The resulting mixture was refluxed until the complete consumption of the starting material $(18 \mathrm{~h})$. The solution was filtered, DCM and $\mathrm{Et}_{2} \mathrm{O}$ (1:5) were added, and the mixture was washed with $0.05 \mathrm{M} \mathrm{HCl}$, saturated aqueous $\mathrm{NaHCO}_{3}$ and water. The solvent was removed to give a black solid which was purified by flash chromatography on silica gel (DCM/Petrol $1 / 1$ eluent). The solvent was removed to give the desired product as a dark purple solid $\left(8 \mathrm{mg}, 10 \%\right.$ yield). ${ }^{1} \mathrm{H}$ NMR $(700$ $\left.\mathrm{MHz}, \mathrm{CDCl}_{3}\right): \delta(\mathrm{ppm})=8.26(\mathrm{~d}, J=8.6 \mathrm{~Hz}, 4 \mathrm{H}, \mathrm{Ph}), 7.92(\mathrm{~d}, J=16.4 \mathrm{~Hz}$, $2 \mathrm{H}$, trans $\mathrm{CH}=\mathrm{CH}), 7.75(\mathrm{~d}, J=8.6 \mathrm{~Hz}, 4 \mathrm{H}, \mathrm{Ph}), 7.30(\mathrm{~d}, J=16.4 \mathrm{~Hz}, 2 \mathrm{H}$, trans $\mathrm{CH}=\mathrm{CH}$ ), 7.08 (s, $2 \mathrm{H}, \mathrm{PhJul}), 7.05(\mathrm{~d}, J=4.3 \mathrm{~Hz}, 2 \mathrm{H}, \beta$-pyrrole), 6.98 (d, $J=4.4 \mathrm{~Hz}, 2 \mathrm{H}, \beta$-pyrrole), 3.37-3.31 (m, 4H, CH2 Jul), 2.83 (t, $J=6.2$ $\left.\mathrm{Hz}, 4 \mathrm{H}, \mathrm{CH}_{2} \mathrm{Jul}\right), 2.03-2.06$ (m, 4H, $\left.\left.\mathrm{CH}_{2} \mathrm{Jul}\right) .{ }^{13} \mathrm{C} \mathrm{NMR} \mathrm{(176} \mathrm{MHz}, \mathrm{CDCl}_{3}\right)$ : $\delta(\mathrm{ppm})=151.74,147.68,145.91,143.80,143.30,136.69,132.29,130.87$ $130.07,127.86,124.40,124.10,121.52,121.22,116.28,50.28,28.02$, 21.75. ${ }^{11} \mathrm{~B}$ NMR $\left(96 \mathrm{MHz}, \mathrm{CDCl}_{3}\right): \delta(\mathrm{ppm})=1.25(\mathrm{t}, \mathrm{J}=33.2 \mathrm{~Hz}) .19 \mathrm{~F}$ NMR $(282 \mathrm{MHz}, \mathrm{CDCl} 3): \delta(\mathrm{ppm})=-138.3(\mathrm{q}, J=33.1 \mathrm{~Hz})$. NSI-FTMS $(\mathrm{m} / \mathrm{z})$ : found $[\mathrm{M}]^{+} 657.2339,[\mathrm{M}+\mathrm{H}]^{+} 658.2418$, calcd. for $\mathrm{C}_{37} \mathrm{H}_{30} \mathrm{BF}_{2} \mathrm{~N}_{5} \mathrm{O}_{4}$ : $657.2360, \mathrm{C}_{37} \mathrm{H}_{31} \mathrm{BF}_{2} \mathrm{~N}_{5} \mathrm{O}_{4}: 658.2438$.

\section{Preparation of 3,5-di(4-vinylpyridinyl)-8-julolidyl BODIPY (JULBD5)}

4-Pyridinecarboxaldehyde ( $40.2 \mathrm{mg}, 0.375 \mathrm{mmol}, 3$ eq.), piperidine $(0.25$ $\mathrm{mL}, 20$ eq.) and glacial acetic acid (0.14 mL, 20 eq.) were added to a solution of 1 (49 mg, $0.125 \mathrm{mmol}$ ) in anhydrous $\mathrm{CH}_{3} \mathrm{CN}(8 \mathrm{~mL})$ containing $4 \AA$ molecular sieves $(1 \mathrm{~g})$. The resulting mixture was refluxed until the complete consumption of the starting material $(4 \mathrm{~h})$. Solvent was removed and solid redissolved in DCM, filtered on silica gel with DCM to remove the starting material and extracted with $5 \% \mathrm{MeOH}$ in DCM to give the final product in $50 \mathrm{mg}$ yield ( $90 \%$ purity). Further purification by flash chromatography on silica gel ( $4 \% \mathrm{MeOH}$ in DCM eluent) gave the desired product as a dark blue solid (35 mg, $49 \%$ yield). ${ }^{1} \mathrm{H} \mathrm{NMR}(700 \mathrm{MHz}$, $\left.\mathrm{CDCl}_{3}\right): \delta(\mathrm{ppm})=8.65-8.63(\mathrm{~m}, 4 \mathrm{H}, \mathrm{Py}), 7.95(\mathrm{~d}, \mathrm{~J}=16.3 \mathrm{~Hz}, 2 \mathrm{H}$, trans $\mathrm{CH}=\mathrm{CH}), 7.48-7.47(\mathrm{~m}, 4 \mathrm{H}, \mathrm{Py}), 7.18(\mathrm{~d}, \mathrm{~J}=16.3 \mathrm{~Hz}, 2 \mathrm{H}$, trans $\mathrm{CH}=\mathrm{CH})$, 7.07 (s, 2H, PhJul), 7.04 (d, J=4.3 Hz, 2H, $\beta$-pyrrole), 6.97 (d, $J=4.4 \mathrm{~Hz}$, 2H, $\beta$-pyrrole), 3.34-3.31 (m, 4H, CH $\mathrm{CH}_{2}$ ), 2.82 (t, J = 6.3 Hz, 4H, $\mathrm{CH}_{2}$ Jul), 2.07-1.99 (m, 4H, CH $2 ~ J u l) . ~{ }^{13} \mathrm{C} N M R\left(176 \mathrm{MHz} \mathrm{CDCl}_{3}\right): \delta(\mathrm{ppm})=$ 151.31, 150.34, 145.62, 143.81, 143.62, 136.15, 131.87, 130.66, 129.83, $123.75,121.25,121.16,120.90,116.01,50.01,27.79,21.45 .{ }^{11} \mathrm{~B}$ NMR (96 $\left.\mathrm{MHz} \mathrm{CDCl}_{3}\right): \delta(\mathrm{ppm})=1.22(\mathrm{t}, J=33.0 \mathrm{~Hz}) .{ }^{19} \mathrm{~F} \mathrm{NMR}\left(282 \mathrm{MHz}, \mathrm{CDCl}_{3}\right)$ : $\delta(\mathrm{ppm})=-138.5(\mathrm{q}, J=33.2 \mathrm{~Hz})$. NSI-FTMS $(\mathrm{m} / \mathrm{z})$ : found $[\mathrm{M}+\mathrm{H}]^{+}$ 570.2628, calcd. for $\mathrm{C}_{35} \mathrm{H}_{31} \mathrm{BF}_{2} \mathrm{~N}_{5}: 570.2641$.

Preparation of 3,5-di(N-methyl-4-vinylpyridinium)-8-julolidyl BODIPY di(hexafluorophosphate) (JULBD6)

Mel (1 mL) was added to a solution of JULBD5 (17 mg, $0.03 \mathrm{mmol})$ in $\mathrm{CH}_{3} \mathrm{CN}(6 \mathrm{~mL})$ and the mixture stirred at $\mathrm{RT}$ for $16 \mathrm{~h}$. Addition of $\mathrm{Et}_{2} \mathrm{O}$ resulted in precipitation of the target compound. The product was recrystallized three times from $\mathrm{DMF}$ by addition of saturated aq. $\mathrm{KPF}_{6}$ and three times by precipitating with $\mathrm{E}_{2} \mathrm{O}$ from DMF. The solid was washed with $\mathrm{Et}_{2} \mathrm{O}$ and dried to yield the target compound as a dark blue solid (20 mg, $75 \%$ yield). ${ }^{1} \mathrm{H}$ NMR $\left(700 \mathrm{MHz}, \mathrm{DMSO}_{-} \mathrm{d}_{6}\right): \delta(\mathrm{ppm})=8.86(\mathrm{~d}, J=6.3$ $\mathrm{Hz}, 4 \mathrm{H}, \mathrm{Py}), 8.17$ (d, J=6.3 Hz, 4H, Py), 8.01 (d, $J=16.2 \mathrm{~Hz}, 2 \mathrm{H}$, trans $\mathrm{CH}=\mathrm{CH}), 7.79(\mathrm{~d}, \mathrm{~J}=16.2 \mathrm{~Hz}, 2 \mathrm{H}$, trans $\mathrm{CH}=\mathrm{CH}), 7.42(\mathrm{~d}, J=4.2 \mathrm{~Hz}, 2 \mathrm{H}$, $\beta$-pyrrole), 7.26 (d, J = 4.1 Hz, 2H, $\beta$-pyrrole), 7.23 (s, 2H, PhJul), 4.30 (s,

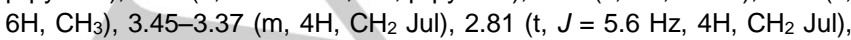
1.99-1.87 (m, 4H, CH 2 Jul). ${ }^{13} \mathrm{C}$ NMR (176 MHz, DMSO-d 6$): \delta(p p m)=$ 151.37, 148.87, 147.65, 145.87, 144.33, 136.61, 132.06, 130.52, 129.40 , $128.85,124.34,122.07,120.98,118.98,50.08,47.64,27.47,21.08 .{ }^{11} \mathrm{~B}$
NMR (96 MHz, DMSO-d $): \delta(p p m)=1.09(\mathrm{t}, J=32.5 \mathrm{~Hz}) .{ }^{19} \mathrm{~F}$ NMR $(659$ MHz, DMSO-d 6 ): $\delta(p p m)=-70.1$ (d, $\left.J=711.3 \mathrm{~Hz}, 12 \mathrm{~F}, \mathrm{PF}_{6}\right),-135.0$ (q, $J$ $\left.=32.6 \mathrm{~Hz}, 2 \mathrm{~F}, \mathrm{BF}_{2}\right)$. NSI-FTMS (m/z): found $\left[\mathrm{M}-\mathrm{PF}_{6}\right]^{+}$744.2663, [M$\left.2 \mathrm{PF}_{6}\right]^{2+} 299.6513$, calcd. for $\mathrm{C}_{37} \mathrm{H}_{36} \mathrm{BF}_{8} \mathrm{~N}_{5} \mathrm{P}: 744.2669, \mathrm{C}_{37} \mathrm{H}_{36} \mathrm{BF}_{2} \mathrm{~N}_{5}$ : 299.6514.

\section{Acknowledgements}

We thank the Leverhulme Trust for financial support, Filipa Dos Santos for help in learning the dissection and recording protocols reported here and Wolfgang Stein for useful discussion regarding the calculation of the SNR. The EPSRC UK National Mass Spectrometry Facility at Swansea University is also thanked for collecting mass spectra of the compounds.

Keywords: Neuron • Fluorescence $•$ BODIPY • Voltage

Response $\cdot$ Structure-Reactivity Relationship

\section{References}

[1] a) B. Carlotti, G. Consiglio, F. Elisei, C. G. Fortuna, U. Mazzucato, A Spalletti, J. Phys. Chem. A 2014, 118, 7782; b) S. Sasaki, G. P. C. Drummen, G. Konishi, J. Mater. C 2016, 4, 2731; c) G. Ulrich, A. Barsella, A. Boeglin, S. Niu, R. Ziessel, ChemPhysChem 2014, 15 , 2693; d) D. Collado, J. Casado, S. Rodríguez González, J. T. López Navarrete, R. Suau, E. Perez-Inestrosa, T. M. Pappenfus, M. M. M. Raposa, Chem-Eur. J. 2011, 17, 498; e) D. Sirbu, C. Turta, A. C Benniston, F. Abou-Chahine, H. Lemmetyinen, N. V. Tkachenko, C Wood and E. Gibson, RSC Adv., 2014, 4, 22733.

[2] a) M. G. Vivas, D. L. Silva, J. Malinge, M. Boujtita, R. Zaleśny, W. Bartkowiak, H. Ågren, S. Canuto, L. De Boni, E. Ishow, C. R. Mendonca, Sci. Rep. 2014, 4, 4447; b) J. Tadeo-León, S. Fomine, M. Bizarro, P. Guadarrama, J. Phys. Org. Chem. 2015, 28, 304; c) Y. Gong, X. Guo, S. Wang, H. Su, A. Xia, Q. He, F. Bai, J. Phys. Chem. A 2007, 111, 5806.

[3] a) C. Coluccini, A. K. Sharma, M. Caricato, A. Sironi, E. Cariati, S Righetto, E. Tordin, C. Botta, A. Forni, D. Pasini, Phys. Chem. Chem Phys. 2013, 15, 1666; b) J. F. Lamère, P. G. Lacroix, N. Farfán, J. M. Rivera, R. Santillanc, K. Nakatani, J. Mater. Chem. 2006, 16, 2913; c) J. Fortage, A. Scarpaci, L. Viau, Y. Pellegrin, E. Blart, M. Falkenström L. Hammarström, I. Asselberghs, R. Kellens, W. Libaers, K. Clays, M. P. Eng, F. Odobel, Chem-Eur. J. 2009, 15, 9058; d) F. Terenziani, D. D'Avino, A. Painelli, ChemPhysChem 2007, 8, 2433.

[4] a) Z. R. Grabowski, K. Rotkiewicz, W. Rettig, Chem. Rev. 2003, 103 3899; b) D. Laage, W. H. Thompson, M. Blanchard-Desce, J. T. Hynes, J. Phys. Chem. A 2003, 107, 6032; c) Z. Diwu, Y. Lu, C. Zhang, D. H. Klaubert, R. P. Haugland, Photochem. Photobiol. 1997, 66, 424; d) A S. Klymchenko, Acc. Chem. Res. 2017, 50, 366

[5] a) Y. Bai, Z.-J. Zhou, J.-J. Wang, Y. Li, D. Wu, W. Chen, Z.-R. Li, C.-C. Sun, J. Phys. Chem. A 2013, 117, 2835; b) M. R. Wasielewski, Chem. Rev. 1992, 92, 435; c) A. Nano, R. Ziessel, P. Stachelek, A. Harriman Chem-Eur. J. 2013, 19, 13528.

[6] a) G. Ulrich, R. Ziessel, A. Harriman, Angew. Chem. 2008, 47, 1184; b) A. C. Benniston, G. Copley, Phys. Chem. Chem. Phys. 2009, 11, 4124; c) T. Kowada, H. Maeda, K. Kikuchi, Chem. Soc. Rev. 2015, 44, 4953.

[7] a) X. Peng, J. Du, J. Fan, J. Wang, Y. Wu, J. Zhao, S. Sun, T. Xu, J. Am. Chem. Soc. 2007, 129, 1500; b) Y. Gabe, Y. Urano, K. Kikuchi, H. Kojima, T. Nagano, J. Am. Chem. Soc. 2004, 126, 3357; c) G. H. 
Summers, J. F. Lefebvre, F. A. Black, E. S. Davies, E. A. Gibson, T. Pullerits, C. J. Wood, K. Zidek, Phys. Chem. Chem. Phys. 2016, 18 , 1059; d) A. C. Benniston, S. Clift, A. Harriman, J. Mol. Struct. 2011, 985, 346; e) D. Bai, A. C. Benniston, S. Clift, U. Baisch, J. Steyn, N. Everitt, P. Andras, J. Mol. Struct. 2014, 1065-1066, 10.

[8] E. N. Fluhler, V.G. Burnham, L. M. Loew. Biochemistry, 1985, 24, 5749

[9] a) N. Boens, B. Verbelen, W. Dehaen, Eur. J. Org. Chem. 2015, 6577; b) H. Lu, J. Mack, Y. Yang, Z. Shen, Chem. Soc. Rev. 2014, 43, 4778 c) Y. Ni, J. Wu, Org. Biomol. Chem. 2014, 12, 3774.

[10] R. Ziessel, T. Bura, J.-H. Olivier, Synlett. 2010, 15, 2304.

[11] K. Rurack, M. Kollmannsbergerb, J. Daub, New J. Chem. 2001, 25, 289.

[12] a) C. Hansch, A. Leo, R. W. Taft, Chem. Rev. 1991, 91, 165. b) J. E. Leffler, E. Grunwald, Rates and Equilibria of Organic Reactions as Treated by Statistical, Thermodynamic, and Extrathermodynamic Methods (Dover edition), Wiley, New York, 1963.

[13] R. A. Marcus, J. Chem. Phys. 1956, 24, 966

[14] R. M. Harris-Warrick, E. Marder, A. I. Selverston, M. Moulins, Dynamic Biological Networks. The Stomatogastric Nervous System, MIT Press, Cambridge, MA, 1992.

[15] a) C. Städele, P. Andras, W. Stein, J. Neuros. Met. 2012, 203, 78; b) W. Stein, C. Städele, P. Andras, J. Neuros. Met. 2011, 194, 224.

[16] S. Preuss, W. Stein, PloS one. 2013, 8, e75678.

[17] A theoretical paper describes a mechanism based on mesoscopic electron transfer in VSDs in which most of the terms in Eq. 1 are discussed and should contribute to the workings of a dye; see L. -S. Li, Nano Lett. 2007, 7, 2981.

[18] For recent examples see: a) J-L. Huang, A. S. Walker, E. W. Miller, J. Am. Chem. Soc. 2015, 137, 10767; b) C. R. Woodford, E. P. Frady, R.
S. Smith, B. Morey, G. Canzi, S. F. Palida, R. C. Araneda, W. B. Kristan Jr, C. P. Kubiak, E. W. Miller, R. T. Tsien, J. Am. Chem. Soc. 2015, 137, 1817.

[19] CrysAlisPro, Agilent Technologies, Version 1.171.36.32

[20] G. M. Sheldrick, Acta Cryst., 2015, A71, 3-8.

[21] G. M. Sheldrick, Acta Cryst., 2008, A64, 112.

[22] O. V. Dolomanov, L. J. Bourhis, R. J. Gildea, J. A. K. Howard, H. Puschmann, J. Appl. Cryst. 2009, 42, 339.

[23] M. J. Frisch, G. W. Trucks, H. B. ScBhlegel, G. E. Scuseria, M. A. Robb, J. R. Cheeseman, G. Scalmani, V. Barone, B. Mennucci, G. A Petersson, H. Nakatsuji, M. Caricato, X. Li, H. P. Hratchian, A. F. Izmaylov, J. Bloino, G. Zheng, J. L. Sonnenberg, M. Hada, M. Ehara, K. Toyota, R. Fukuda, J. Hasegawa, M. Ishida, T. Nakajima, Y. Honda, O. Kitao, H. Nakai, T. Vreven, J. A. Montgomery, Jr., J. E. Peralta, F. Ogliaro, M. Bearpark, J. J. Heyd, E. Brothers, K. N. Kudin, V. N. Staroverov, T. Keith, R. Kobayashi, J. Normand, K. Raghavachari, A Rendell, J. C. Burant, S. S. Iyengar, J. Tomasi, M. Cossi, N. Rega, J. M. Millam, M. Klene, J. E. Knox, J. B. Cross, V. Bakken, C. Adamo, J. Jaramillo, R. Gomperts, R. E. Stratmann, O. Yazyev, A. J. Austin, R. Cammi, C. Pomelli, J. W. Ochterski, R. L. Martin, K. Morokuma, V. G. Zakrzewski, G. A. Voth, P. Salvador, J. J. Dannenberg, S. Dapprich, A. D. Daniels, O. Farkas, J. B. Foresman, J. V. Ortiz, J. Cioslowski, and D. J. Fox, Gaussian 09, Revision D.01, Gaussian, Inc., Wallingford CT, 2013.

[24] G. J. Gutierrez, R. G. Grashow, J. Vis. Exper. 2009, 23, 1207.

[25] U. B. Hedrich, C. R. Smarandache, W. Stein, J. Neurophys. 2009, 102 2866. 


\section{FULL PAPER}

Rhythm of the Light: Extended donor-acceptor BODIPY derivatives were examined as new optical neuron probes. The dyes were tested by recording the activity of neurons in the stomatogastric ganglion (STG) of the brown crab Cancer pagurus. A simple structure reactivity relationship was derived.

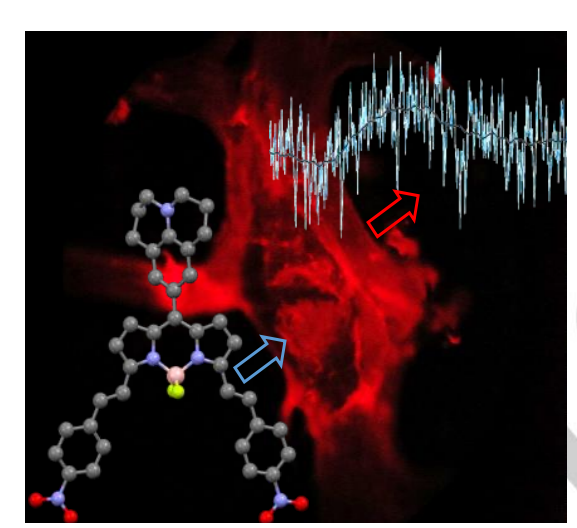

Dumitru Sirbu, John B Butcher, Paul. G. Waddell, Peter Andras, Andrew C. Benniston*

Page No. - Page No.

Locally Excited State-Charge

Transfer State Coupled Dyes as

Optically Responsive Neuron Firing

Probes 
